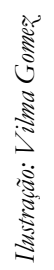




\title{
Trabalho e Vida Pessoal: O EquILÍBRIO NECESSÁRIO
}

\author{
Daisy Valmorbida Stepansky* \\ Lucia França*
}

\begin{abstract}
Resumo
Este artigo descreve o cenário da globalização e suas implicações no processo de trabalho. Os autores enfatizam a importância dos programas de equilíbrio entre o trabalho e a vida pessoal, e seus benefícios para os trabalhadores, organizações e sociedade. Eles analisam ainda o número de horas dedicadas ao trabalho, especialmente entre os executivos, mulheres e trabalhadores mais velhos, e as mudanças de atitudes necessárias para aumentar o bem-estar, a motivação e a produtividade. Algumas sugestões são apresentadas de forma a incluir os programas de equilíbrio trabalho e vida pessoal nas agendas organizacionais.
\end{abstract}

Palavras chave: Equilíbrio; Trabalho; Vida pessoal; Bem-estar; Aposentadoria; Envelhecimento; Gênero.

\section{Trabalho E TeCnOlogia: o Cenário das MUdANÇAS}

A "revolução tecnológica" - a terceira da era moderna tornou-se obrigatória nos estudos sobre as sociedades globalizadas. As novas tecnologias remodelaram a base material da sociedade desde as últimas décadas do século XX, contribuindo para a interdependência global, alterando as relações entre os Estados nacionais, as sociedades e as economias. Grandes transformações alteraram definitivamente as relações de trabalho e impuseram mudanças significativas à vida pessoal e familiar dos trabalhadores. A operacionalização do capitalismo também se alterou, assumindo uma maior flexibilidade de gerenciamento, descentralização das empresas e relações internas e externas, com outras empresas, em sistema de rede.

A difusão das novas tecnologias informacionais modificou a estrutura de emprego e é um dos fatores mais importantes para a compreensão das mudanças nas estruturas sociais. Há, entretanto, variações determinadas pela cultura e pelas instituições específicas de cada uma das sociedades, no interior do mesmo processo de globalização da economia.

Alguns cientistas sociais, com expectativa otimista, acreditam que a nova economia atribua mais valor às profissões com grande

\footnotetext{
* Doutora em Comunicação e Cultura pela UFRJ; Mestre em Sociologia pelo IUPERJ; Bacharel e Licenciada em Ciências Sociais pela UFRGS; Professora Ajdjunta IV do PPGSD/UFF (Programa de Pós-Graduação em Sociologia e Direito da UFF. E-mail: daisystepansky@terra.com.br

** Psicóloga social, PbD em Psicologia pela Universidade de Auckland, Nova Zelândia. Mestre em Psicologia Socialpela UFRJ. Professora titular do Programa de Pós-Graduação em Psicologia da Universidade Salgado de Oliveira (Universo). E-mail: luciafranca@ luciafranca.com. Site: http:// mmm.luciafranca.com
}

Recebido para publicação em: 29/02/08. conteúdo de informação e de conhecimento em suas atividades. É evidente, no entanto, o fortalecimento do capital diante do trabalho, para o que contribuem vários fatores: a individualização das relações no processo produtivo, o aumento do desemprego e enfraquecimento dos movimentos de trabalhadores, a ampliação da força de trabalho, pela incorporação maciça e normalmente discriminatória, das mulheres; e o alargamento das fronteiras nacionais pelo capital. Dentre as características do processo de mudança destaca-se o desmonte das políticas públicas de bemestar e a internacionalização dos mercados financeiros.

O setor de serviços inclui não apenas as profissões de grande especialização e alto nível de qualificação, mas também segmentos residuais e arcaicos. Dentre as diferenciações das estruturas de emprego dos países desenvolvidos e as dos países periféricos, poderíamos destacar o volume da população empregada, sua qualificação e rendimentos em cada um dos pólos - moderno ou arcaico - do setor de serviços. Há também um entrelaçamento diferenciado no tempo e na intensidade das características de mudança da estrutura de emprego, embora possamos arriscar algumas generalizações para os períodos 1920-1970 e 1970-1990.

É bastante significativo o aumento da população empregada na indústria no primeiro período (1920-1970), quando as sociedades desenvolvidas se tornaram pós-rurais, e uma redução no segundo (1970-1990), quando ocorreu o intenso processo de reestruturação econômica e tecnológica, e essas sociedades se tornaram pós-industriais. A tendência atual, dominante na maior parte dos países desenvolvidos, é a redução do emprego industrial e o aumento do emprego em serviços, em informação e na produção de elementos relacionados à informática. Nesses países também se ampliam os serviços sociais, os serviços de distribuição, e serviços pessoais, de certa forma remanescentes da estrutura não industrial de emprego. 
No período 1970-1990, pós-industrial, os tipos de serviços (com exceção dos empregos domésticos), não desapareceram, mas mudaram de conteúdo, diversificaram-se, requalificaram-se. Os serviços do setor de saúde e as atividades de atendimento a idosos estão entre as atividades que mais crescem. A par das novas ofertas da ciência e da tecnologia, a sociedade informacional convive com o significativo crescimento da demanda criada por uma população idosa mais numerosa.

Uma breve comparação das estruturas de emprego dos países desenvolvidos com as estruturas da periferia capitalista permite a constatação de grandes diferenças. O período anterior a 1970, marcado pela intensa industrialização central, é contemporâneo de grandes esforços, altos custos e de escassos resultados de industrialização em grande parte da periferia, submetida à exportação desvantajosa de recursos naturais e à importação de produtos industrializados, capitais e tecnologia. Posteriormente, quando da "desindustrialização" dos países centrais e da emergência de suas "economias de serviços", houve o deslocamento das indústrias para a periferia, em busca de menores custos de produção e de menores conflitos trabalhistas. A nova divisão internacional da produção e a mundialização do processo produtivo foram viabilizadas pela tecnologia informacional e pelas alterações políticas de cunho neoliberal, implantadas pelo mesmo processo de globalização da economia - uma globalização na qual há um centro e uma periferia, e é indispensável que existam as desigualdades da periferia para que se mantenha a intensa acumulação do centro.

O que Arrighi (1997) ${ }^{1}$ denomina Revolução Organizacional - integração vertical e racionalização dos processos de produção - relaciona-se com a relação entre o processo produtivo e as bases sociais, e pode significar que essa fase do capitalismo começou a destruir as criadas pelo wellfare e a transformar suas instituições, apontando para a necessidade de novas soluções para as relações entre trabalhadores e processo de trabalho, particularmente entre os trabalhadores em envelhecimento, que ingressaram na vida produtiva em outros cenários tecnológicos, econômicos e institucionais.

A tecnologia da informação oferece as condições para que ocorram a internacionalização e a interdependência, não apenas do capital e dos mercados, mas também da força de trabalho, através das redes coligadas das empresas multinacionais e de suas redes internacionais. Porém, ainda é pequena a internacionalização do mercado para a maior parte dos trabalhadores do mundo. A força de trabalho dos países periféricos, pouco competitiva e desqualificada diante das tecnologias informacionais, é integrada apenas em situações muito específicas no mercado globalizado. O papel fundamental no processo de globalização é do capital financeiro, pela sua capacidade de se adaptar perfeitamente ao modelo de rede. O dinheiro é versátil enquanto mercadoria e flui celeremente através dos limites nacionais.

\section{TEMPo E TRABalHo: A REORGANIZAÇão DA VIDA}

A reorganização das relações pessoais e familiares com o tempo evidencia a diminuição das horas dedicadas a lazer, entre 1973 e 1994 nos Estados Unidos (CASTELLS, 1999)², e à mídia a partir dos anos 80: menos horas dedicadas a leitura de livros, à TV e a filmes, possivelmente devido ao aumento do número de horas ocupadas pelo trabalho. A pesquisa de Charles Piller citada por Castells revelou, entretanto, que cresce o interesse por outras formas de utilização dos recursos tecnológicos disponíveis: participação em discussões políticas gerais ou comunitárias, cursos e ensino à distância.

Nas grandes cidades das sociedades industrializadas, as pesquisas demonstram que a mídia é a segunda atividade em quantidade de tempo ocupado, após apenas do trabalho. O tempo dedicado às ocupações diárias e às atividades no interior das casas tem importância maior para as mulheres e para quem mora só, característica crescente na atualidade.

A comunicação mediada por computadores expande-se mais lentamente que a televisão, e se populariza rapidamente apenas nos países industrializados e entre os segmentos mais abastados dos países periféricos, nas áreas metropolitanas maiores e mais ricas. Embora as pesquisas sobre o tema sejam ainda escassas, dados preliminares revelam que a grande maioria dos usuários de computador localiza-se nas faixas mais altas de renda (CASTELLS, 1999) 3 , é do sexo masculino (67\%), mais da metade tem entre 18 e 34 anos e profissões predominantemente nas áreas de educação, vendas e engenharia. As mulheres e os idosos são minoria dentre os usuários de computador. Os usos mais freqüentes estão relacionados com atividades de trabalho.

Em outra pesquisa, desenvolvida pela Fundação Européia para a Melhoria da Qualidade de Vida e Ambiente de Trabalho acerca do desenvolvimento da "casa eletrônica", também citada

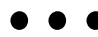

\section{A tecnologia da informação} oferece as condicões para que ocorram a internacionalização e a interdependência, não apenas do capital e dos mercados, mas também da força de trabalho, através das redes coligadas das empresas multinacionais e de suas redes internacionais. Porém, ainda é pequena a internacionalização do mercado para a maior parte dos trabalhadores do mundo. 
por Castells (1999) $)^{4}$ é caracterizado o novo estilo de vida pela "centralidade da casa" e pelo individualismo. Ampliam-se as vendas de acessórios eletroeletrônicos de utilização individual e porções de alimentos individualizadas. A estrutura familiar mantém suas características tradicionalmente autoritárias, centradas na autoridade masculina. A divisão das tarefas domésticas ou a sua concentração sobre as mulheres não se alterou, e os padrões culturais conservadores convivem com modernos aparelhos domésticos elétricos e eletrônicos.

A tecnologia permite que se trabalhe menos para a manutenção do mesmo nível de produção, mas seu impacto no tempo real de trabalho e nos horários da vida do trabalhador ainda é indeterminado, afirma Castells (1999) $)^{5}$. Na maior parte das sociedades desenvolvidas ocorre diversificação geral do tempo de trabalho, dependendo das empresas, redes, empregos, ocupações e características dos trabalhadores. Inserem-se novas medidas da capacidade produtiva de cada trabalhador e novas possibilidades de utilização do tempo, como, por exemplo, a compatibilização de tarefas domésticas e familiares com os procedimentos de trabalho.

A revolução informacional, como Lojkine $(1995)^{6}$ denomina o conjunto das transformações tecnológicas que se seguem à revolução industrial, está apenas começando e já altera consideravelmente as formas de interação da rede social e do processo produtivo. As divisões tradicionais - produtores e improdutivos - nas sociedades capitalistas desenvolvidas perdem parte do sentido atribuído pela divisão do trabalho, entre os assalariados que produzem bens materiais e os assalariados que trabalham com informação.

Há uma "reprofissionalização do trabalho", polivalência, formação qualificadora e pluridisciplinar, para quase todos os segmentos de trabalhadores, operários, burocratas e prestadores de serviços. As mudanças nas valorizações de profissões e de trabalhadores de serviços, originadas nas transformações do processo produtivo impõe-se às relações sociais. Não se pode afirmar, entretanto, que esteja em desenvolvimento um processo de retorno ao que poderia ser denominado "democracia" de pequenos prestadores de serviços, proprietários de seus próprios instrumentos de trabalho.

Aceleram-se as qualificações e a familiaridade com instrumentos profissionais novos e se alternam ao longo da vida de um mesmo trabalhador. As qualificações são extintas, porque se tornam desnecessárias muito antes do final da vida profissional. O trabalhador ou investe permanentemente em sua reprofissionalização, ou se torna obsoleto antes mesmo de envelhecer. As novas formas de interação e de comunicação por rede ainda desafiam sociólogos, antropólogos e psicólogos sociais. As formas de solidariedade e de individualização, a simultaneidade de formas de comunicação e de isolamento são um campo instigante para os estudiosos das grandes sociedades massificadas, particularmente dos grandes conglomerados urbanos. As potencialidades das novas máquinas informatizadas para o desenvolvimento individual, social e econômico estão, possivelmente, ainda pouco exploradas e talvez sejam ainda pouco conhecidas, mas já imprimem elementos novos às personalidades contemporâneas.

A relação com o trabalho é um dos elementos mais importantes dentre as mudanças sociais desencadeadas pela nova estrutura pro- dutiva: carreira, substituída por emprego ou serviço, que substitui a rígida burocracia implantada pela revolução industrial. A aparente flexibilização das formas de funcionamento do capitalismo na atualidade - mudanças nas relações com tempo, espaço e propriedade dos instrumentos de trabalho - convive com maior liberdade para as pessoas administrarem suas vidas e novas formas de controle da produção, por produtos, e não mais por tempo de trabalho.

A relação do trabalho com o tempo é organizadora da vida social e individual, e permite ao trabalhador, segundo Richard Sennett (1999) ${ }^{7}$, o planejamento e a administração de sua vida, a médio e longo prazos: tempo de constituir família, de ter filhos e de adquirir bens, por exemplo. As relações de sociabilidade e de solidariedade, o círculo de amigos, os locais de moradia são definidos ou profundamente marcados pelas possibilidades de planejamento profissional, ou desorganizados pela atual flexibilização e imprevisibilidade das relações de trabalho.

As empresas organizadas em

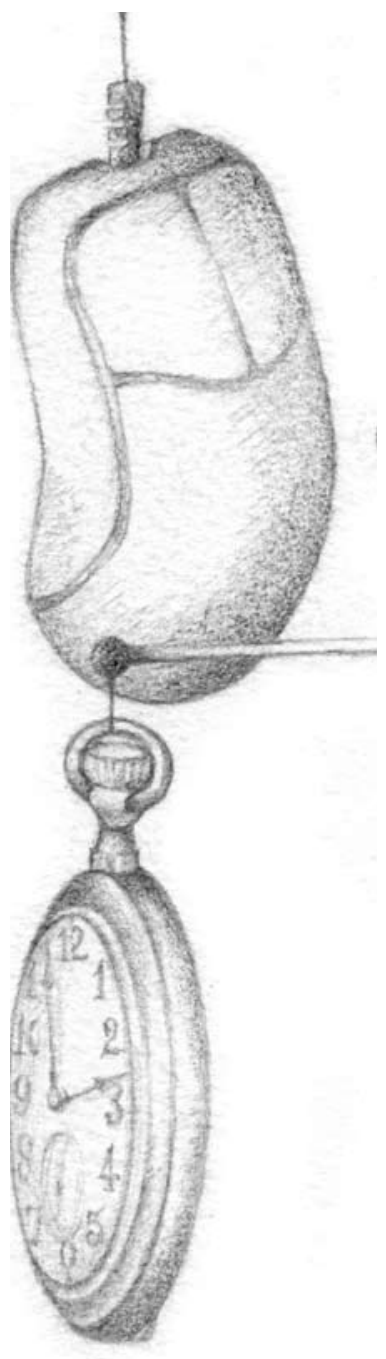
rede, por exemplo, têm uma estrutura mais leve e mais flexível, porém são mais instáveis, não geram vínculos e não permitem a organização da vida dos trabalhadores em uma perspectiva de tempo. A estrutura produtiva se impõe às estruturas sociais, às relações familiares, ao caráter individual. Não há mais longo prazo, como afirma Sennett $(1999)^{8}$. É rompida a narrativa linear e cumulativa que organiza as experiências de vida. No mundo que se torna flexível, as narrativas pessoais passam a ser de curto prazo, alteram-se as relações de tempo, de lugar e de trabalho. $\mathrm{O}$ tempo se fragmenta e a instabilidade é a normalidade.

Contraditoriamente, a prisão criada pela estrutura tradicional de emprego submetia o trabalhador à engenharia produtiva, apropriava-se de seu tempo, contabilizado pela produção, esvaziado de criação, mas the oferecia a possibilidade de compor o projeto de vida. A rotina decompunha o trabalho, degradava o trabalhador, mas, de certa forma, o protegia. Para Scott Lasch e John Urry (SENNET'T, 1999)', a flexibilidade é o fim do capitalismo organizado da forma como chegou às últimas décadas do século XX.É o tempo de reorganização do controle e das relações pessoais com o tempo, com o espaço e com o trabalho.

Em estudo recente, Guimarães $(2004)^{10}$ analisa a inserção de jovens no processo de trabalho na Região Metropolitana de São Paulo, onde constata alterações na mesma direção apontada por 


\section{$O$ desemprego recorrente $e$}

a informalidade do mercado

de trabalho produzem

insegurança para o

trabalhador "recém-chegado"

ao mundo profissional e

problematiza a trajetória de

vida dos trabalhadores em

processo de envelhecimento.

Sennett, Lasch e Urry e nos países centrais: rompe-se a relação direta entre emprego e trabalho, o modelo de trabalhador permanente, empregado em horário integral. Saem de cena os contratos de longa duração e desenvolve-se um novo modelo de trabalho parcial, auto-emprego, trabalho no domicílio e alternância de carreiras. O desemprego recorrente e a informalidade do mercado de trabalho produzem insegurança para o trabalhador "recémchegado" ao mundo profissional e problematiza a trajetória de vida dos trabalhadores em processo de envelhecimento.

A reação operária aos primeiros impactos da automatização dos processos produtivos na indústria automotiva no Brasil (OLIVEIRA, 1996) ${ }^{11}$ evidenciou que, embora a tecnologia automatizada oferecesse possibilidades concretas para a transformação das condições laborais e de vida dos trabalhadores, tal não era percebido massivamente. O grau de informação que o trabalhador tem das novas tecnologias de automação, a forma de organização do trabalho na empresa, o nível de organização dos empregados, nível educacional, acesso a fontes de informação, cultura geral, entre outras, são variáveis significativas para a natureza da reação dos trabalhadores às novas tecnologias.

O estudo aponta para a existência de diferentes formas de percepção e de reação à automação, e de suas implicações na vida e no processo de trabalho: reação passiva ou defensiva, quando o trabalhador parece não estar envolvido com a problemática da tecnologia, percebe preponderantemente seus efeitos negativos e reage com resignação; reação ofensiva, quando ele - está a par da tecnologia, procura informar-se sobre seus efeitos sobre a sociedade, além de ativar estratégias de luta, analisa os efeitos positivos e negativos da tecnologia, e reivindica participação nos benefícios de que ela é capaz de trazer à sociedade e ao mundo do trabalho; e reação ainda não ofensiva, quando há o conhecimento do problema, mas ainda não há reação. Nesse período em que a automação ainda era incipiente, também eram incipientes as reflexões sobre suas conseqüências.

Há muitos anos são realizados estudos e previsões de desemprego tecnológico em países com diferentes níveis de desenvolvimento (DE MASI, 2000) ${ }^{12}$, mas ainda são escassas as propostas de redução das jornadas de trabalho, de flexibilização da jornada, de acordo com as especificidades profissionais, ou do tempo para a aposentadoria. Ou ainda, poderíamos acrescentar, como se dará a interação das pessoas fora do processo de trabalho com as novas tecnologias que transbordam do processo produtivo e impõem-se à vida social. Posteriormente, prevê De Masi $(2000)^{13}$, mudanças sociais e culturais se aplicarão à vida da sociedade, redimensionando as relações com o trabalho, com o tempo,com a criação, com a arte, com a vida, conclui.

\section{Trabalho E Saúde: os ESFORÇOS Para REORGANIZAR A VIDA}

Em alguns países cresce a inserção de programas de work-life balance-equilibrio entre o trabalho e vida pessoal dentro das organizações empresariais, o que representa o controle das pessoas sobre quando, onde e como querem trabalhar. Esse equilíbrio é obtido quando a organização aceita e respeita o direito do indivíduo ter a sua vida plena, dentro e fora do trabalho, e isso gera benefícios mútuos para os indivíduos, organizações e sociedade.

Na proposta do equilíbrio entre trabalho e vida pessoal, é papel da organização buscar estratégias para que o trabalho seja realizado de forma mais agradável, reduzindo o estresse e flexibilizando o tempo do trabalhador. Tal flexibilidade possibilita a participação do trabalhador em atividades que promovam a sua saúde e bem-estar, e em obrigações de natureza familiar, especialmente no atendimento e acompanhamento na assistência aos filhos e familiares idosos.

No caso da mulher, especialmente as que têm ou querem ter filhos, o equilíbrio entre trabalho e vida pessoal é um imperativo. Soluções individuais precárias e com problemas de continuidade e de custo, como empregadas domésticas, babás e o apoio familiar, são utilizadas, embora estejam longe de substituir os ainda raros empregos de meio expediente ou as creches, que atendam as crianças com custos e horários compatíveis com os rendimentos familiares. A obrigatoriedade da creche no Brasil se limita, muitas vezes, ao papel, e poucas mães (e menos ainda pais trabalhadores) podem usufruir desse benefício. A estes fatores deve ser somada a escassa participação masculina no cumprimento das tarefas domésticas e no cuidados com crianças, característica ainda marcante da cultura de diversos países e, no Brasil, o grande número de famílias chefiadas exclusivamente por mulheres - cerca de $25 \%$ na média nacional e de $30 \%$ nas metrópoles. A falta de instituições sociais de apoio e os fatores culturais problematizam sobremaneira a participação feminina no mercado de trabalho na faixa etária reprodutiva.

Um estudo realizado com pais e mães solteiras no Reino Unido, Japão e na Finlândia sobre o conflito trabalho-família e família-trabalho (CHANDOLA, T; MARTIKAINEN, P; BARTLEY, M. et al, 2004) ${ }^{14}$ demonstrou que o equilíbrio entre o trabalho e as obrigações familiares contribuiriam para a melhoria da saúde mental para os trabalhadores de ambos os sexos, em sociedades industriais.

O equilíbrio de tempo, trabalho e vida, associado a uma 
compensação salarial digna, permitiria ao trabalhador o usufruto do bem-estar, a assistência familiar e a promoção da saúde, resultados naturalmente esperados pela sua dedicação ao trabalho e à organização. A grande maioria dos trabalhadores têm, entretanto, pelo menos metade do seu dia comprometida na preparação, no trajeto e no trabalho propriamente dito. Outras dez horas são destinadas ao descanso, à alimentação e ao asseio básico. Portanto, menos de duas horas são disputadas entre o relacionamento familiar e as obrigações e rotinas domésticas diárias. Ainda assim, dependendo das condições de vida e do tipo de trabalho desenvolvido, muitos nem dispõem desse tempo, se residirem distante do trabalho ou realizarem programas extras de educação ou especialização.

Trabalhar muitas horas também faz parte da realidade daqueles que exercem posições de liderança, como os executivos, cujas horas extras se estendem aos finais de semana. Como argumentado por De Masi $(2000)^{15}$, na maioria das vezes, as horas extras são produzidas pela falta de objetividade nos processos de trabalho, podendo ser observada nas reuniões intermináveis ou nas rotinas recheadas de burocracia inútil, que apontam para a necessidade de estabelecer prioridades e replanejar o tempo.

No caso específico dos executivos, cujo trabalho está intimamente associado ao poder de decisão e à competição permanente, evidencia-se a ambivalência provocada pelo estresse e pelo nível de satisfação com o cargo. A dedicação à organização limita o tempo de convivência com a família e com o parceiro, e o tempo destinado ao consumo de bens culturais. Essa restrição é observada na promoção da saúde, em função da dificuldade de uma alimentação balanceada, de ter o mínimo de horas de sono necessárias, da prática de atividades físicas regulares ou de exames médicos periódicos.

Em pesquisa realizada com 300 líderes de grandes organizações brasileiras, França $(2008)^{16}$ apontou que eles trabalhavam, em média, mais de 50 horas por semana, fato observado também nas realizadas por Feldman $(2002)^{17}$ e Fletcher $(2003)^{18}$. Cerca de $65 \%$ dos executivos da pesquisa de França dedicavam pelo menos quatro horas de seus finais de semana ao trabalho. Contraditoriamente, esses mesmos executivos, a maioria constituída por homens, quando simularam uma ordenação de possíveis atividades a serem realizadas na aposentadoria, priorizaram o tempo para os filhos e parceiros, ignorando o fato de que, à época da aposentadoria, seus filhos provavelmente estariam crescidos, independentes e com interesses e necessidades diversos do que dedicar tempo aos pais, agora aposentados. Da mesma forma, seus parceiros poderiam estar acostumados a viver sem a sua presença e, na aposentadoria, isso poderia provocar uma sensação de 'estar sobrando' no ambiente doméstico..

França $(2008)^{19}$ ressaltou que, apesar das expectativas dos executivos de dedicar mais tempo à família e às atividades de lazer na aposentadoria, metade dos investigados considerou seus empregos como sendo mais importantes do que seus outros papéis na sociedade, sobretudo as relações familiares, os relacionamentos sociais e os serviços comunitários. A ambivalência entre o desejo e o uso do tempo é mais evidente no grupo dos executivos mais velhos. Isso representa um desafio, pois estes tendem a trabalhar mais ainda (60 ou mais horas por semana). Esses dados são coerentes com o fato de que os rela- cionamentos familiares constituem-se na temática mais votada pelos executivos para ser inserida nos programas de preparação para a aposentadoria (PPA).

Especialistas em Recursos Humanos devem estar alertas para o desligamento dos trabalhadores excessivamente envolvidos com o trabalho e a dificuldade deles em aceitar novos estilos de vida, com o deslocamento do tempo livre para si próprios, para a família e para projetos pessoais na aposentadoria. A transição para a aposentadoria desses trabalhadores requer aconselhamento e apoio psicossocial.

O desequilíbrio no tempo de vida pessoal e vida de trabalho podem ser tão fortes que, mesmo para aqueles que estão prestes a se aposentar e assumir o controle total sobre o seu tempo, não raro emerge um sentimento de incapacidade em administrá-lo ou uma sensação de falta de propósito na vida. Daí a necessidade de um programa que priorize a realização de metas de vida dentro das rotinas diárias, a escolha das atividades mais prazerosas, o repasse dos conhecimentos e desenvolvimento de novas habilidades, numa dinâmica de atualização de processos e idéias.

O maior preditor para atitudes positivas frente à aposentadoria foi a diversidade na alocação de tempo, sendo pequena a diferença observada entre as atividades que os executivos afirmaram realizar e as intenções de alocação de tempo na aposentadoria $\left(\right.$ FRANÇA, 2008) ${ }^{20}$. Beehr (1986) ${ }^{21}$ e Atchely (1989) ${ }^{22}$ também notaram que as atividades dos indivíduos, após a aposentadoria, foram consistentes com as atividades de lazer realizadas antes do evento. Lim e Feldman (2003) ${ }^{23}$ concluíram que os indivíduos

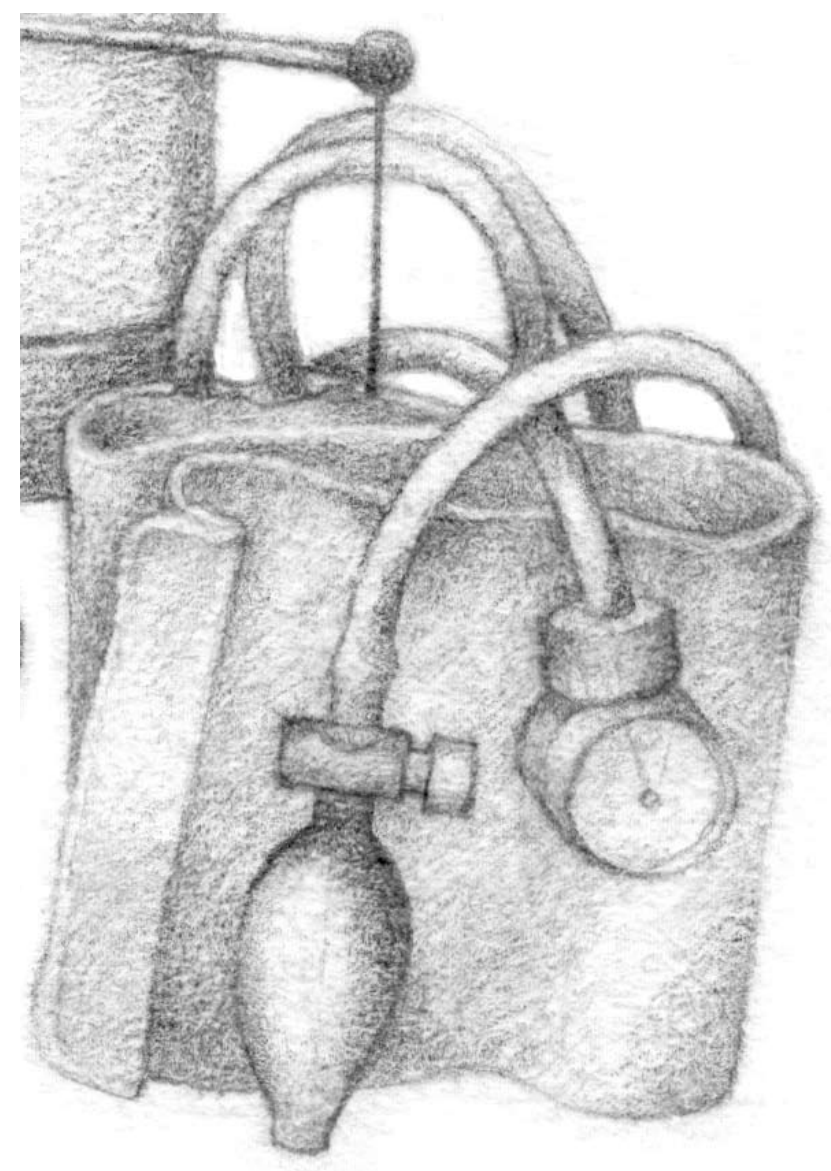


não transformam tanto seus hábitos quando envelhecem e estruturam o tempo da mesma maneira que antes da aposentadoria, embora coloquem os hobbies e o trabalho voluntário no lugar das atividades de trabalho.

Com o envelhecimento das sociedades, é preciso investigar e sistematizar o conhecimento sobre as características, as necessidades e os interesses dos aposentados que desejam participar positivamente da rede social. Políticas e programas inovadores que estimulem o aproveitamento mais racional do tempo podem reforçar a auto-estima do trabalhador e trazer resultados igualmente satisfatórios para a empresa, na forma produtividade, integração e melhoria no relacionamento dos trabalhadores mais velhos com outros mais jovens.

Numa época em que se prioriza no país o crescimento acelerado da economia, definindo metas de crescimento econômico, é fundamental que seja lembrada a importância do desenvolvimento paralelo dos indicadores sociais e da qualidade de vida dos indivíduos participantes do processo de trabalho. As organizações devem considerar que não é o grande consumo de tempo do trabalhador que leva à produtividade, mas que, ao contrário, é o ambiente organizacional saudável que deve apoiar o trabalhador. A flexibilização de tempo oferece o equilíbrio entre as responsabilidades de trabalho e as necessidades individuais e familiares, produzindo uma diferença efetiva na qualidade de vida para todos.

\section{CoNCLUSÃO}

As questões demográficas são extremamente relevantes para a elaboração dos projetos de desenvolvimento econômico, tecnológico e social. Os países centrais continuarão sofrendo grande pressão das correntes migratórias oriundas da periferia, com taxas de natalidade significativamente mais elevadas, escassos empregos e políticas sociais deficitárias.

Alguns países já enfrentam com sucesso os desafios apresentados pelas novas relações entre tecnologia e trabalho. $\mathrm{Na}$ Nova Zelândia, por exemplo, verifica-se uma queda acentuada na taxa de desemprego e o aumento dos trabalhadores idosos no mercado de trabalho. Há uma visão otimista em relação ao equilíbrio entre trabalho e vida pessoal, e um atendimento prioritário às crianças e aos jovens como uma forma de evitar que estes migrem na busca de melhores oportunidades no exterior (NEW ZEALAND. Ministry of Social Development, 2002) ${ }^{24}$. Davey e Cornwall $(2003)^{25}$ consideram improvável que o país consiga vencer o desafio do envelhecimento pela imigração de trabalhadores estrangeiros jovens ou pelo aumento da taxa de natalidade, e investem na importância que os trabalhadores mais velhos terão na economia.

No Canadá, outro exemplo de enfrentamento da problemática: o ministro do Trabalho e Habitação, Joseph Frank Fontana, afirmou que o governo e as empresas devem se esforçar na busca do equilíbrio entre a proteção aos trabalhadores e o apoio à flexibilidade e à produtividade no local de trabalho (FÓRUM URBANO MUNDIAL, 2005) ${ }^{26}$.

Estudo realizado com mil trabalhadores pela Work Foundation (ISLES, Nick, 2004) ${ }^{27}$ demonstrou que, apesar da enorme propaganda existente na Grã-Bretanha em prol dos programas de work-life balance, apenas $21,5 \%$ dos trabalhadores declararam ter flexibilidade de tempo entre o trabalho e a vida privada. Apesar disso, o estudo apontou que a satisfação com o trabalho é mais importante que o pagamento dele advindo. Demonstrou também que o trabalho é avaliado como essencial para o bemestar, especialmente quando os trabalhadores têm o controle sobre o que fazem.

O estudo da Work Foundation indicou ainda que as atitudes da equipe frente ao equilíbrio do tempo de trabalho e vida pessoal são mais importantes do que propriamente a redução das horas trabalhadas. Isso aponta para a importância do apoio mútuo e da solidariedade frente às necessidades da equipe que não são apenas laborativas, mas individuais, sociais e familiares.

No caso brasileiro, as condições demográficas ofereceriam oportunidades promissoras para o país. A precária qualificação profissional, a urbanização extremamente intensa e as condições de vida nas grandes metrópoles são, entretanto, entraves ao desenvolvimento humano e econômico, e desafios imediatos às políticas públicas. Nesse contexto, não há dúvidas de que o investimento em ciência e tecnologia será fundamental para conviver com um mercado cada vez mais competitivo: o investimento em conhecimento é mais permanente que o realizado em máquinas.

Além do investimento na educação, as organizações devem oferecer maior liberdade de escolhas para o trabalhador dentro do processo laboral, apresentando maior flexibilidade de horários, viabilizando o equilíbrio entre a vida pessoal e a participação no processo produtivo. Tal flexibilidade, vital para a saúde e o bem-estar, mereceu destaque no Fórum Econômico Mundial, em 2006, quando foram incluídos na agenda temas como a distribuição do tempo, a sexualidade e a felicidade, como complementares a discussões sobre a crise energética, as economias emergentes da China e da Índia, o terrorismo e o crescimento da economia global (BERLINK, Deborah, 2006) ${ }^{28}$. No ano seguinte, o Fórum de Davos priorizou o desenvolvimento e a sustentabilidade do meio ambiente, as mudanças climáticas e a água (WORLD ECONOMIC FORUM, 2007)29. É o reconhecimento da importância do desenvolvimento humano para a lucratividade do processo produtivo.

A liberdade obtida pelo controle do tempo, otimizando os processos de trabalho e priorizando o equilíbrio do tempo de trabalho e vida, é uma demanda emergente nas gestões de pessoas. Por sua vez, as organizações que adotam o programa de work-life balance acabam por atrair, selecionar e manter os melhores profissionais. Os programas de equilíbrio entre trabalho e vida pessoal trazem resultados mensuráveis sobre o aumento do nível de comprometimento e motivação dos trabalhadores, mas a sua importância ainda não foi totalmente absorvida pelas organizações.

Medidas de melhoria das condições específicas de trabalho, como redução de carga horária pela adoção de meio-expediente, compensação de horas, licenças anuais, ou dias para atendimento médico a familiares, inclusão de novos benefícios, como de planos de saúde, psicológico e odontológico, creches, academias de ginástica, restaurantes e clínicas no local de trabalho; ou a adoção de programas de administração e racionalização de tempo devem ser acompanhadas de práticas de responsabilidade social das organizações com os empregados, com suas famílias e com 
o entorno social e ambiental.

A oferta de condições para o desenvolvimento pessoal, para a criatividade e para a participação positiva no trabalho são fatores significativos na atualidade das organizações. É uma nova revolução no mundo do trabalho, com a absorção de novas formas de responsabilidade, de empregabilidade e de sustentabilidade, em que o processo produtivo contribuirá para o desenvolvimento humano e para a melhoria das condições de vida da sociedade.

\section{Notas}

1 ARRIGHI, Giovanni. A ilusão do desenvolvimento. Petrópolis : Vozes, 1997.

2 CASTELLS, Manuel. A era da informação: economia, sociedade e cultura. São Paulo : Editora Paz e Terra, 1999. v. 1, 2, 3.

3 Id. ibid.

${ }^{4}$ Id. ibid.

5 Id. ibid.

6 LOJKINE, Jean. A revolução informacional. São Paulo : Cortez, 1995.

SENNETT, Richard. A corrosão do caráter: as conseqüências pessoais do trabalho no novo capitalismo. Rio de Janeiro : Record, 1999.

8 Id. ibid.

9 LASCH ,Scott; URRY, John. Apud. SENNETT, Richard. (1999) op. cit.

${ }^{10}$ GUIMARÃES, N. A. Trajetórias Inseguras, autonomização incerta: os jovens e o trabalho em mercados sob intensas transições ocupacionais. In: CAMARANO, A. A. (Org.). Os novos idosos brasileiros: muito além dos 60?. Rio de Janeiro : Ipea, 2004.

${ }^{11}$ OLIVEIRA, Graziela. Automação e reação operária: estudo de caso em São Bernardo do Campo. João Pessoa : Ed. Universitária/UFPB, 1996.

${ }^{12}$ DE MASI, Domenico. O futuro do trabalho: fadiga e ócio na sociedade pós-industrial. Trad. Yadyr A. Figueiredo.3. ed. Brasília : Ed. UnB, 2000.

${ }^{13}$ Id. Ibid.

${ }^{14}$ CHANDOLA, T; MARTIKAINEN, P; BARTLEY, M. et al. Does conflict between home and work explain the effect of multiple roles on mental health? A comparative study of Finland, Japan, and the UK. International Journal of Epidemiology, v.33, n. 4, p. 884-893, 2004.

15FRANÇA, Lucia. O desafio da aposentadoria: o exemplo dos executivos do Brasil e da Nova Zelândia. Rio de Janeiro : Rocco. 2008.

${ }^{16}$ Id. Ibid.

${ }^{17}$ FELDMAN, Daniel. Managers' propensity for work long hours. A multilevel analysis. Human Resource Management Review, v.12, p. 339-357, 2002.

${ }^{18}$ FLETCHER, W. Beating the 24/7: how business leaders achieve a successful work/life balance. [Electronic resource], Boulder, CO.: NetLibrary. 2003.

${ }^{19}$ FRANÇA, Lucia. (2008). op. cit.

${ }^{20}$ Id. Ibid.

${ }^{21}$ BEEHR, Terry. The process of retirement: a review and recommendations for future investigation. Personnel Psychology, v.39, n.1, p. 31-55. 1986.

22 ATCHLEY, Robert. A continuity theory of normal aging. The Gerontologist, v. 29, n. 2, p.183-190, 1999.

${ }^{23}$ LIM, Vivian; FELDMAN, Daniel. The impact of time structure and time usage on willingness to retire and accept bridge employment. International Journal of Human Resource Management, v. 14, n.7, p.1178-1191, 2003.
${ }^{24}$ NEW ZEALAND. Ministry of Social Development. Improving well-being for all New Zealanders: briefing to the incoming Minister. Wellington, 2002.

${ }^{25}$ DAVEY,J. A.; CORNWALL, J. Maximising the potential of older workers. NziRA Wellington: Victoria University of Wellington. 2003. Future Proofing New Zealand Series.

${ }^{26}$ FÓRUM URBANO MUNDIAL Relatório de planos e prioridades no Canadá (2004-2005). 2005.. Disponível em: <www.habitatjam.com/webuploads/members/oFontana Joseph Bio English.pdf > Acesso em: $27 \mathrm{fev}$. 2007.

${ }^{27}$ ISLES, Nick. The Joy of work?. United Kingdom : The Work Foundation. 2004. Disponível em: < http://www.theworkfoundation.com>. Acesso em: 27 fev. 2008.

${ }^{28}$ BERLINK. Deborah. Na agenda de Davos, felicidade e vida sexual. Globo Online, Economia. Disponível em: $<$ http://oglobo.globo.com $>$ Acesso em: 27 fev. 2008.

${ }^{29}$ WORLD ECONOMIC FORUM. Annual Meeting. 2007, Davos, Switzerland, from 24-28 January 2007. Newsletter. Disponível em: < http:// www.siteresources.worldbank.org/INTANNREP2K5/Resources/13972931127325073491/51563_Portuguese.pdf> Acesso em: 27 fev. 2008.

\section{ABSTRACT}

Daizy Valmorbida Stepansky; Lucia França. Work and personal life: the necessary balance.

This article describes the globalization scenario and its implications for the work. process. The authors emphasize the importance of programs to establish a balance between work and personal life, with their benefits to workers, organizations, and society. They also analyze the number of hours spent on work, especially among executives, women and aging workers, and the attitude changes to increase well-being, motivation, and productivity. Some suggestions are offered in order to include work-life balance programs into organizational agendas.

Keywords: Work-life balance; Well-being; Retirement; Aging; Gender.

\section{RESUMEN}

Daizy Valmorbida Stepansky; Lucia França. Trabajo y vida personal: el equilibrio necesario.

El artículo describe el escenario de la globalización y sus implicaciones en el proceso de trabajo. Las autoras enfatizan la importancia de los programas de equilibrio entre trabajo y vida personal y sus consiguientes beneficios para los trabajadores, organizaciones y sociedad. Asimismo, analizan las consecuencias del número de boras trabajadas, especialmente entre los brasileños, ejecutivos, mujeres y trabajadores en proceso de envejecimiento, y los cambios de actitud para poder aumentar el bienestar, la motivación y la productividad. Se presentan algunas sugerencias con el objeto de incluir programas de equilibrio entre trabajo y vida personal en las agendas organizacionales.

Palabras clave:Equilibrio; Trabajo; Vida Personal; Bienestar; Jubilación; Envejecimiento; Género. 